\title{
Design of Bus Integrated Information System Based on Wireless Transmission
}

\author{
Yang Genghuang \\ DaGu south Road No. 1310 Hexi District Tianjin China \\ Tianjin Key Laboratory of Information Sensing and \\ Intelligent Control; \\ Tianjin, China \\ ygenghuang@126.com \\ Li Xiang \\ DaGu south Road No. 1310 Hexi District Tianjin China \\ Tianjin Key Laboratory of Information Sensing and \\ Intelligent Control; \\ Tianjin, China \\ 364754917@qq.com
}

\author{
Su Xin \\ Hongqi Road No. 278, Nankai District, Tianjin, China \\ Chengxi Power Supply Bureau, Tianjin POWER GRID \\ Tianjin, China \\ susin@126.com
}

Zhang Jia

Xiditou Beichen District Tianjin China

Tianjin Bohai Vocational Technical College

Tianjin, China

ashe_11@126.com

\begin{abstract}
As the result of the widely usage of Electrical equipment in bus, Corresponding fault in inner equipment has become a common problem of its operation, increasing the difficult and time of fixing...This paper develops a new bus integrated information wireless transmission system based on IPC2378 chip, for the purpose to extract the information of bus electrical fault. This system collects the OBD (OBD) data of buses and then transmits the data to the information center and users' terminals through wireless transmission technology. Therefore, it allows the user to achieve the operation record depending on the actual demands, and then decreases the fixing period of the bus.
\end{abstract}

Keywords-OBD; wireless; transmission system; LPC2378FBD144; the SD card; IC card

\section{I . INTRODUCTION}

Statistical data shows that if the fault of the bus operation have effective analysis, then traffic accidents decreases the rate of $37 \%-52 \%$, which reduces the casualties and property losses and results in more social and economic benefits[1]. Meanwhile, the main aim of OBD is to detect the fault of the bus operation and reduce sits sick mileage, so as to enhance the safety performance of the bus. At present, the starting point of the research on OBD data is the impact of cars on the environment and the perspective of energy consumption. [2] By this way, The engine operating conditions can be judged by both the data of exhaust emissions and the engine itself.

\section{II . SYSTEM STRUCTURE}

As shown in Fig .1 the system architecture, The bus integrated information wireless transmission system consists of vehicle module, network system, user terminals and the Information Center. Bus mounted module collects and sends the OBD data by means of the CAN bus. The network system is the basis of wireless transmission, allowing the user to achieve the information sent by bus mounted module through intelligent mobile phone, tablet computer and so on. Information center is responsible for the storage of data. Since this system works in the harsh environment on the bus, it requires the system have a good compatibility, adaptability and effective data transmission, in order to collect the information accurately and send successfully.

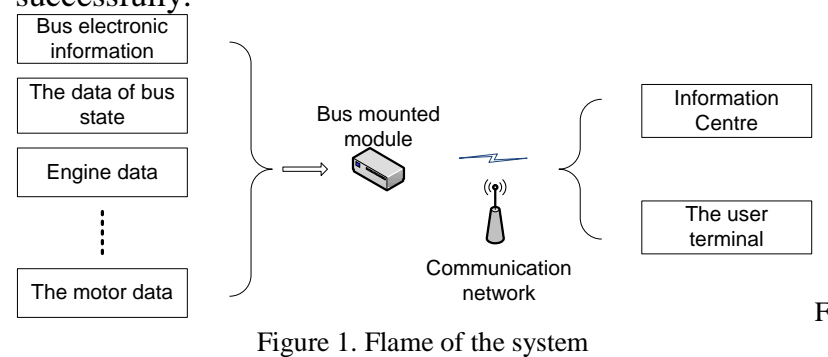

\section{A. The Power module}

Because power supply in bus is $12 \mathrm{~V}$ or $24 \mathrm{~V}$, separate power supply modules are required to tackle the problems in communication, data processing and wireless transmission, to ensure the reliability of data transmission [3].Thus, the Power module should have the following features: input range of DC is $9-36 \mathrm{~V}$, the isolation of DC is $1500 \mathrm{~V}$, short circuit protection, overvoltage protection, the metal is six sided shielding bag, small ripple and noise.

\section{B. The storage module}

SD cards are used in the storage module, because the SD card itself has a fast read-write speed, large memory capacity and other advantages. In addition, LPC2378 Integrates SD interface inside. Moreover, the form of SD card storage is that storage files can use any way to store on time depending on the time with the analytical document software to read file data[4]. When the SD card memory is full, the newly received data will take the place of the earliest one. Finally, According to the date, the information will be reflected and stored from CAN files. 


\section{The Management module}

The IC card is a key to start the work of vehicle modules. Each vehicle module is compiled with one ID identification number, only corresponding IC card and the higher authority of the IC card can start the work of vehicle modules, thus improving the safety of data transmission

\section{Communication module}

The differential transceiver of CAN bus transceiver AMIS42665 is provided by CAN bus protocol controller it coincides with ISO-11898 formal standard, including meet the requirements of $24 \mathrm{~V}$.its highest works rate is $1 \mathrm{Mb} / \mathrm{s}$, to meet the requirements of the standard physical layer[5]. It is widely used in communication and control between the ECU in buses.

\section{E. The main control chip}

The LPC2378FBD144 MCU is made by NXP company, with a Streamlined instruction set, the ultra low power waste microcontroller based on ARM7DMI-S, is applicable to all kinds of serial communication [6]. Because of its low power consumption and flexible mode of development, this chip has become a hot research topic. Its main features are:

(1) Low voltage, low power waste, the working voltage is in the range of $3.0 \sim 3.6 \mathrm{~V}$.

(2) The chip has a 10 bit A/D converter.

(3) The chip has four 32 bit timers, setting the clock flexibly.

(4) The frequency of oscillator inside the chip operates between $1 \sim 24 \mathrm{MHz}$.

(5) The chip has 4 UART serial, making it convenient for users to communicate among machines.

(6) It provides 5 data port from the $\mathrm{P} 0^{\wedge} 0 \sim \mathrm{P} 4 \wedge 0$, and more system processing function. 4 interrupt functions provided by users from peripheral data ports.

(7) With JTAG simulation debugging interface, to facilitate debugging software simulation.

(8) The chip can provide more storage, and also provide more RAM to facilitate the operation processing function. its Flash is $512 \mathrm{~KB}$ on chip inside, [7-10]

(9) With dual CAN interface in CJA1050 application

\section{SOFTWARE DESIGN}

The software requires a good portability, so it is written in Keil4 environment in modular way. The main modules in software system are:

(1) the main program: initialize the hardware module firstly, scan and manage Keyboard information, and jump to each function module;

(2) the CAN transceiver procedures: receive and transmit the data information;

(3) the WIFI module program: assist the host computer to receive data information;

(4): SD card module program: store information data

(5) IC card program: identify and store the basic information of the vehicle equipment

\section{A. receiving information}

The equipment transmits all the data through CAN bus and sends to the MCU of information wireless transmission devices, and stores the information into SD card. After that it transmits the data to host computer by WIFI wireless devices.

\section{B. The flow of main program}

The main program is prepared for data transmission first, and then initializes corresponding hardware. When confirming all of the relevant flag bit, the system completes the initialization. After that, the hardware will store the internal fault code into the SD card through the CAN bus. The third step, the data will be divided into priority transmission and transmits to the host computer through the wireless network. The last step is judging the time, to prove the right of data transmission. If the time is wrong, then return to the step 2

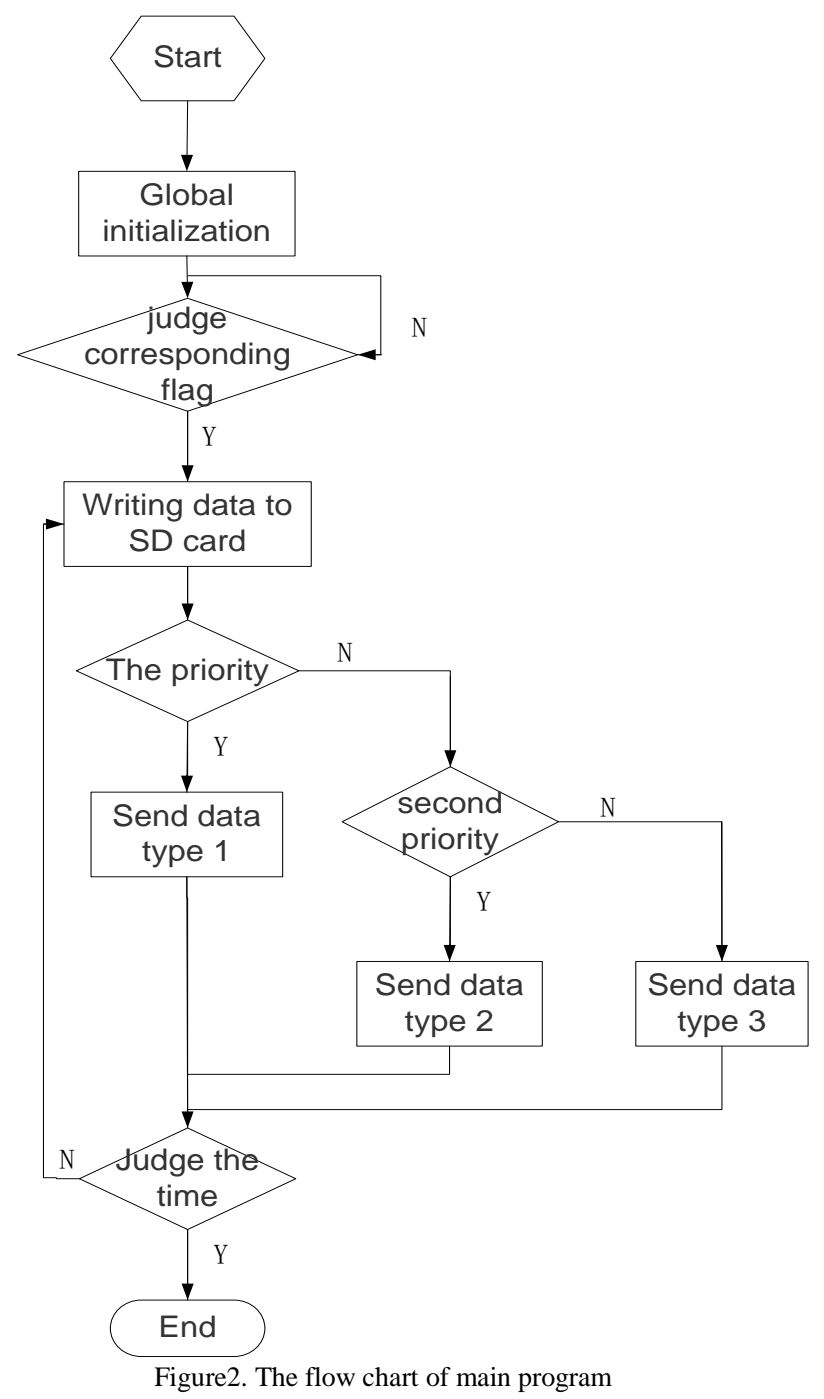

\section{The Initialization program flow}

The Initialization program flow chart is shown in Figure $* *$. After the program starts, the first step is to initialize each hardware module, and then entering to the main loop, after that scanning the circulation process constantly and entering the corresponding function module according to the requirement. 


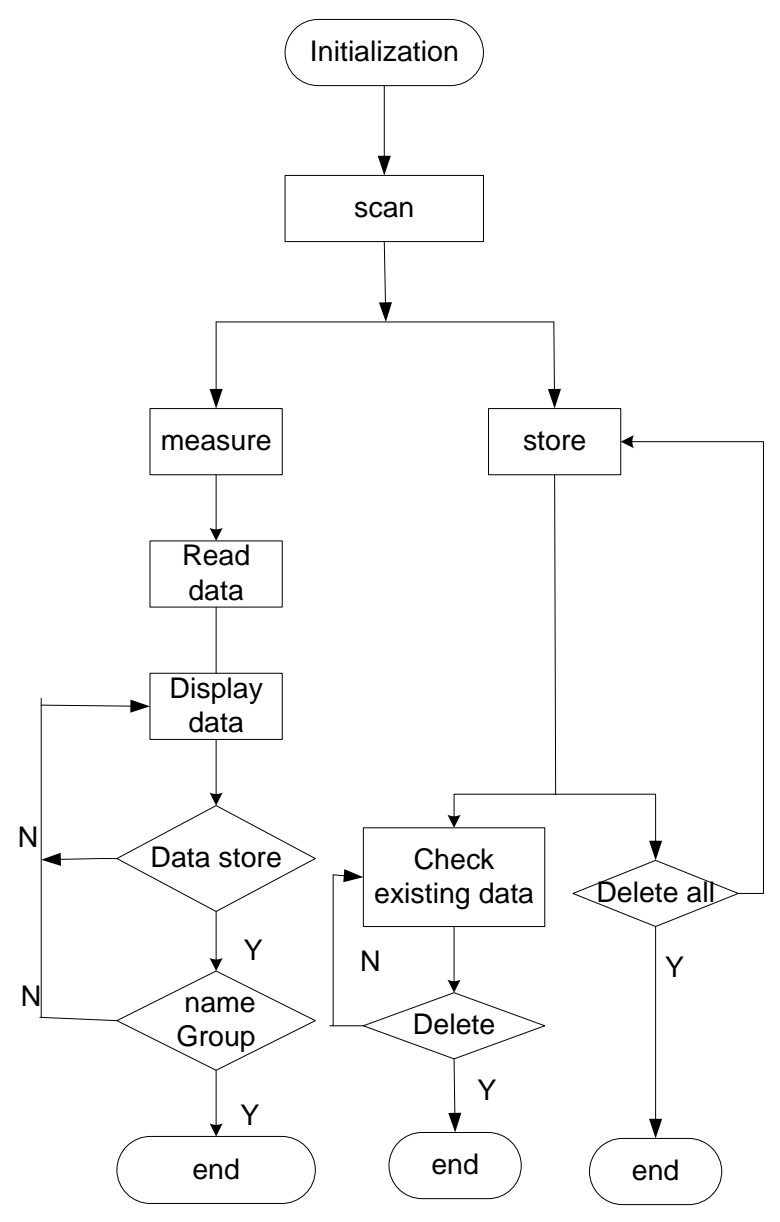

Figure3. The flow chart of initializing measure and store program

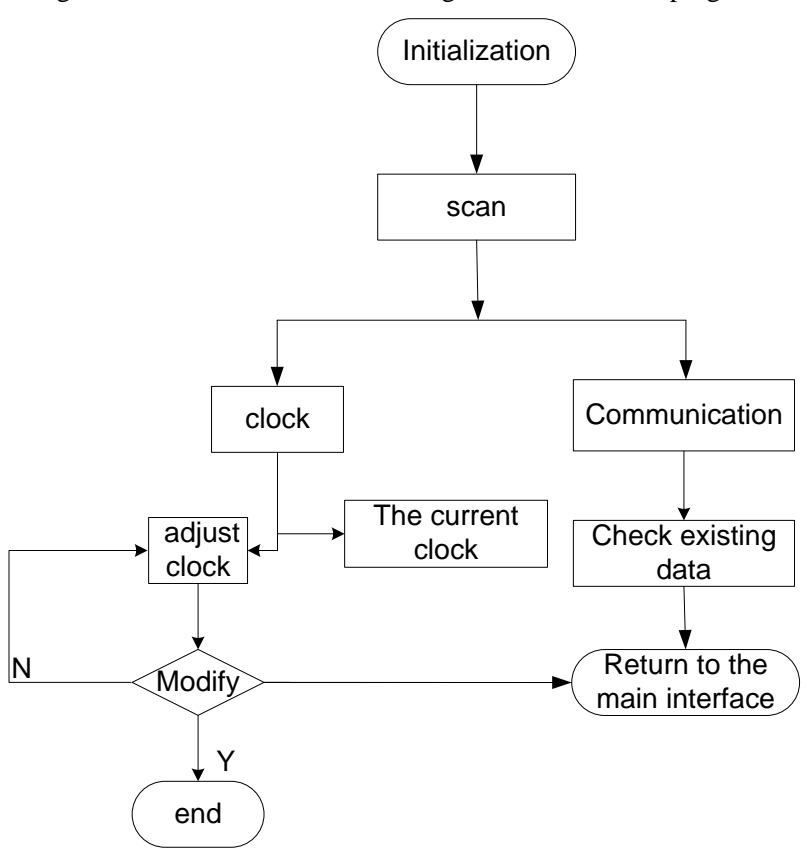

Figure4. The flow chart of initializing clock and communication

program

For the measurement module, after initialization, the module enters to the scanning step, and after that, enters the measurement interface, to receive serial port data. If the program does not enter the measurement interface, then returns to re scan again. After entering the measurement interface, the next step is to measure the data storage, packet number, time of storage. However, if it fails to do that, then returns to the button scan to re-execute the program. After completes the storage number, the program is completed.

Finally, it is the data modify and deleting function programs. These programs also require initialization firstly, and then scan the signals, access to existing data, modify and delete the data group number. If the third step program execution is not successful, the program returns to scan again. In addition, this program is similar to the program of modify the clock information.

\section{USER TERMINALS}

The system has two user terminals, the PC terminal and the intelligent mobile phone terminal. Due to intelligent mobile phone terminal is incapable to realize all demands of the system, therefore it only equips only real-time vehicle fault function software. The corresponding interfaces are shown in Fig .5 to Fig .6. In Fig .5, ten kinds of real-time data is monitored in its interface.

The PC version is more comprehensive. Users can store the data through EXCLE. When the information is required, they can be viewed easily by EXCLE.

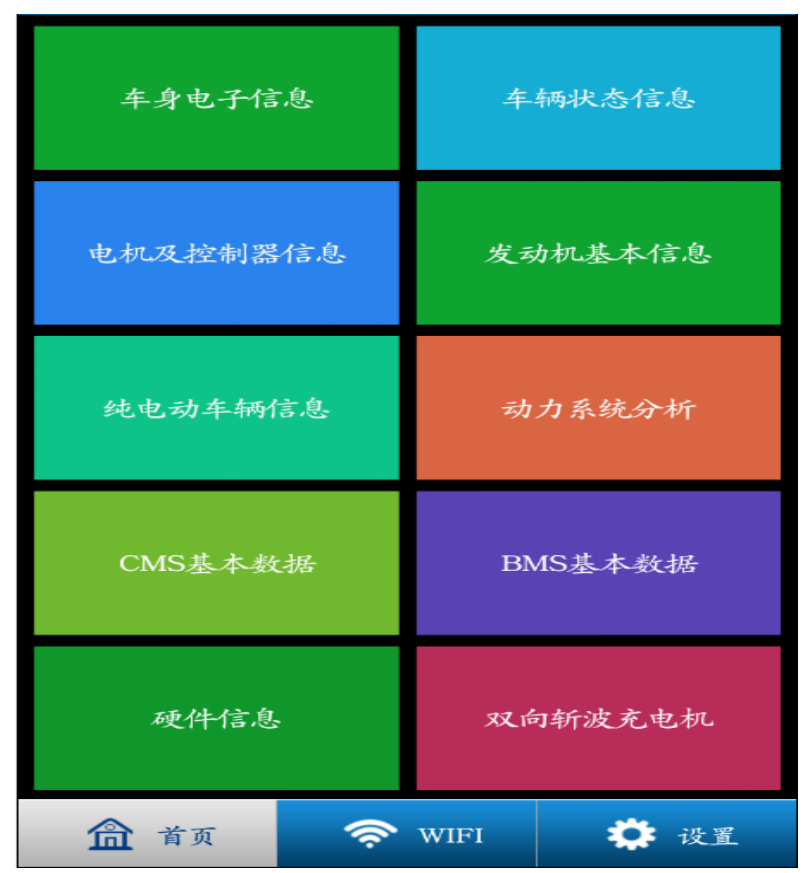

Figure5. The interface of the intelligent mobile phone terminal 


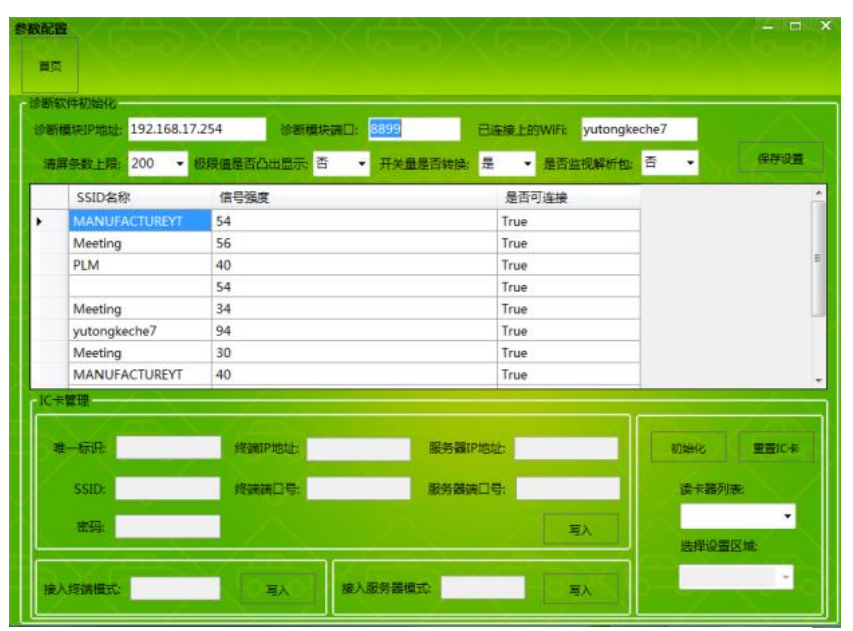

Figure6. The interface of the PC terminal

TEST RESULTS

\begin{tabular}{|c|c|c|c|c|}
\hline 名称 & $\begin{array}{l}\text { 加速踏板开度 (插 } \\
\text { 电) }(\%)\end{array}$ & $\begin{array}{l}\text { 制动踏板开度（插 } \\
\text { 电） }(\%)\end{array}$ & 储能系统SOC(\%) & 当前车速 $(\mathrm{km} / \mathrm{h})$ \\
\hline 实时值 & -. & -. & 85.20 & 13 \\
\hline 最大值 & -. & -- & 85.20 & 13 \\
\hline 最小值 & -. & -- & 85.20 & 13 \\
\hline 关联项 & - & -- & -- & .. \\
\hline 车身 & 状态 & 电机信息 & 发动机 & CMS \\
\hline
\end{tabular}

Figure7. The test result of the intelligent mobile phone terminal

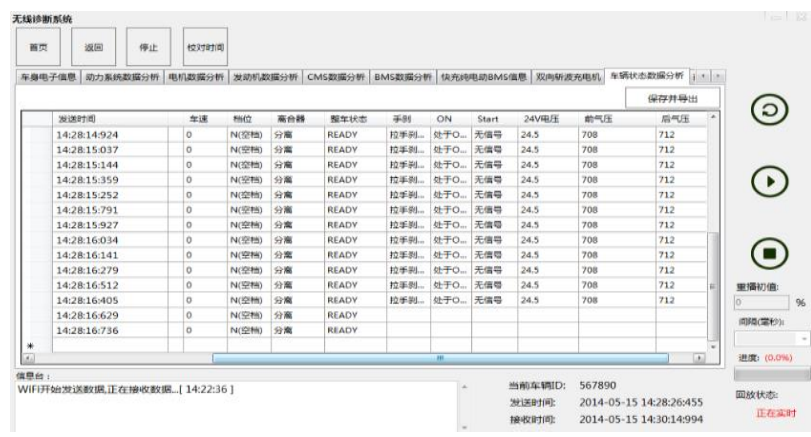

Figure8. The test result of the PC terminal

The test results show that this system allows internal data in bus to be visualized. Both the PC terminal and intelligent mobile phone terminal are capable to receive and display the information accurately. Moreover, it is convenient for the user to view data information in real time. The test results as figure $* *$

\section{CONCLUSION}

The accuracy of bus integrated information of wireless transmission systems has reached the expected result. During the debugging process, this system works stable .it is proved that this system can be used in remote monitoring, data collection and transmission. The application of wireless communication system will play a key role in the network times. As the device has a mobile acquisition and can access to data information speedy, it has practical and popularization value in this area.

\section{REFERENCES}

[1] Platt G.,Cornforth D.,Berry A.Review of minigrid research and development around the world: accelerating the deployment of "Smart Minigrids"in APP countries. http://www. asiapacificpartnership. org /english/project_roster.aspx . 2009

[2] A.Griffo,D.Lauria."Optimal Reclosure Time for Improving Power System Dynamic Behaviour". IEE roc.-Gener . 2005

3] Dugui Wu,Zhiheng Xu.Development and prospect of microprocessor-based protection relays in China. Transmission and Distribution Conference and Exhibition 2002 . 2002

[4] Q. C. Le,B.T.T. Phan,T.Q.D. Khoa."Computation of Reclosing Time and Suitable Gain of Automatic VoltageRegulator". Power India Conference, 2006, IEEE . 2006

5] Negnevitsky M,,Pavlovsky V.Neural networks approach to online identification of multiple failures of protection systems. Power Delivery,IEEE Transactions on . 2005 R. Nicole, "Title of paper with only first word capitalized," J. Name Stand. Abbrev., in press.

[6] Li Cheng Sun,Zheng Wu. Relay Protection Based on Multi-Agent System[J]. Advanced Materials Research . 2013 (760)

[7] Guo Jia Rong,Ran Feng,Bi Zhuo,Xu Mei Hua. A Compiler for Ladder Diagram to Multi-Core Dataflow Architecture[J]. Advanced Materials Research . 2012 (462)

[8] Cunfeng Kang,Chong Wang,Chunmin Ma,Xudong Huang, Renyuan FEI. Run-time system based on LinSERCANS and Soft-PLC $[\mathrm{J}]$. Frontiers of Mechanical Engineering in China 2009 (2)

[9] Zmaranda, Doina,Gabor, Gianina,Vancea, Codruta. Verification of PLC programs Used in Real-Time Applications[J]. Journal of Computer Science and Control Systems . 2010 (1)

[10] Gergely, Eugen Ioan,Husi, Geza,Yildirim, Sahin. PLC Programs Design Using Signal Interpreted Petri Networks[J]. Journal of Computer Science and Control Systems . 2009 (1) 